\title{
An interview with the chairman of the rural practices subcommittee
}

Scratch a rural doctor and find a contented countryman. Such an aphorism might have been true once, but the supposed peace of medicine in the shires has been disturbed in recent years by growing rumblings from discontented doctors and disgruntled rural pharmacists. Such is the strength of feeling that splinter groups dissatisfied with their existing representative organisation have arisen in both professions. It so happens that the General Medical Services Committee is now led by a rural dispensing doctor from Yorkshire, Dr Michael Wilson, and this session the rural practitioners subcommittee elected a new chairman.

Does this mean that we shall hear more about rural practice? To find out a member of the editorial staff visited Dr David Farrow, the new chairman, at his country practice in Hawkhurst on the Kent/Sussex border.

As a member of Kent Local Medical Committee for 20 years and its chairman for five, and a member of the GMSC for 11 years and of its rural practices subcommittee since 1968, Dr Farrow has acquired a broad perspective of general practice. Surprised and a little apprehensive at being elected to lead his 6000 or so rural colleagues, he confessed to apprehension because the commitment required will bear heavily on him and his small group practice. $\mathrm{He}$ is, however, not only well briefed on the difficulties that have.prompted the recent unrest among the rural practitioners but willing to be blunt when he believes that medicopolitical home truths are necessary.

Dr Farrow's election to the chair in 1984 coincided with publication of the first annual report of the Rural Dispensing Committee, of which he is a member (p 1091). This mixed committee of rural doctors, pharmacists, and lay people, chaired by Sir Alan Marre, was set up as the result of the long running review of rural dispensing chaired by Sir Cecil Clothier. That the Rural Dispensing Committee was set up at all would seem a minor medicopolitical miracle, given the strong and bitter differences that had grown between dispensing doctors and rural pharmacists. Sadly, some bitterness persists, further fanned by pharmacists indignant that dispensing doctors will be allowed to dispense for sale to their patients drugs on the recently introduced blacklist in the course of treatment.

The new chairman is trenchantly critical of extremist elements in both professions who he believes "are basically not really interested in patients." $\mathrm{He}$ sees the eight year moratorium on changes in dispensing arrangements and the subsequent Clothier agreement as a remarkable achievement on behalf of patients, as well as a valuable protection for pharmacists and doctors. "If you consider that the doctors started from the stand that patients should have the right on each and every occasion to decide where his or her prescription should be dispensed and that the pharmacists wanted dispensing done only by pharmacists it says a tremendous amount for the negotiators on both sides and for the skill of Cecil Clothier that agreement was eventually reached."

\section{Government's attempt to stop dispensing}

Recalling what many older rural doctors had forgotten-and what younger ones may never have known-Dr Farrow pointed out that in the Family Doctor Charter negotiations of 1964-6 the government wanted to remove (except for the "serious difficulty provision") all dispensing rights from doctors. Furthermore, some medicopoliticians had been willing to concede the change. That threat to rural practice had galvanised him into standing for election to the Kent Local Medical Committee. The representatives of rural practitioners, however, had fought hard to keep the right to dispense and they had won the battle but almost jeopardising the charter negotiations. This had been just as well for the future of rural practice because, he said, in many instances the ability to dispense enabled a practice to sustain an extra partner whose presence made the workload, particularly the on call liabilities, tolerable and so maintained a satisfactory service for patients.

At one time many doctors did not find dispensing particularly profitable-indeed some had lost money-and Dr Farrow pointed out that while in part this had been due to an unsatisfactory capitation method for remunerating dispensing, in part it had been because of bad management by doctors. Town doctors might not realise that a dispensing practitioner had to put a considerable amount of capital-around $£ 12000$ for an average three man practice-into setting up the dispensing arrangements and purchasing a stock of drugs, so unless that was done efficiently practices could lose money. The imposition in the ' $60 \mathrm{~s}$ and '70s of government income policies-with their ceiling on annual pay rises-had, paradoxically, galvanised many dispensing doctors to improve the way they managed and financed dispensing because they just could not afford to lose any money. Anyway, dispensing for doctors had been preserved and he believed that most practices now did it efficiently.

\section{Rural dispensing committee}

The first year of the Rural Dispensing Committee, the origins and workings of which are described at $p$ 1091, had been hard work but it had made reasonable progress and Dr Farrow believed that it was the key to ensuring that patients in rural areas received satisfactory medical and pharmaceutical services. A disturbing revelation had been the inadequacy of family practitioner committees' records on rural dispensing-some committees had no dispensing lists-and it had been a major administrative exercise to bring lists of dispensing patients up to date, an added burden for committees already in the throes of a reorganisation. Both "sides" had mellowed to the work of the Rural Dispensing Committee and mutual respect had developed between them-Sir Alan Marre, its chairman, like Cecil Clothier before him, had "elbowed out unreasonableness." Rural pharmacists had acquired a greater understanding of the financial impact on a doctor's practice of a new village pharmacy and doctors appreciated the competitive commercial pressures under which pharmacists had to operate. It was an anxious time for both groups, he said, but the limited rural dispensing "cake" had to be fairly distributed, a point that he hoped young doctors entering rural practice would understand.

The pharmacists had woken up much more quickly to the implications of Clothier than had the doctors because the issue 
loomed larger in pharmaceutical politics than in medicopolitics. There had been little or no feedback from local medical committees, even the predominantly rural ones, about their reactions to the Clothier discussions. This lack of response had occurred despite the committees being kept regularly informed about them in circulars and annual reports from the GMSC. Ignorance had bred suspicion and this had no doubt contributed to the difficulty on the doctors' side in launching the voluntary levy scheme to recompense doctors and pharmacists whose dispensing arrangements were adversely affected by decisions under the Clothier agreement. But Dr Farrow was cautiously optimistic that the scheme was now up and running.

With hindsight Dr Farrow believed that more information in the professional press would have alerted rural doctors to what was happening. As it was, the implications of the Clothier agreement had not generally sunk in-except to the handful of practices in dispute about local dispensing arrangements-until pharmacists had started to protest because when new patients were added to dispensing lists some family practitioner committees had allowed the head of the family to sign the option form requesting dispensing by their doctor. Pharmacists wanted separate forms for each patient to sign. Doctors had reacted angrily to this because they believed that signing on for dispensing should not be any more difficult than signing on for general medical services.

Was there any truth in pharmacists' accusation that some doctors' dispensing services were not properly supervised and that "unqualified" staff were left to do the dispensing ? Dispensing doctors customarily used dispensing technicians-the same type of staff as used by pharmacists, replied Dr Farrow. "We train and supervise our staff, and delegate our dispensing activities where appropriate; but remember, the doctor carries the can." As to the view of pharmacists that doctors should stick to prescribing he described this as a reflection of pharmacists' attempts to find a role in society. Dispensing was now pretty straightforward with most drugs prepacked and though pharmacists might claim to know more than general practitioners about adverse reactions and incompatible drugs the younger generation of doctors were well versed in therapeutics, and doctorsparticularly group practices-were increasingly using computers programmed with pharmaceutical information.

Did rural patients prefer their doctors to dispense for them? "Absolutely: once they've experienced dispensing by doctors they want to continue it. There is a psychological advantage in the doctor handing over drugs that he has prescribed. Furthermore, the patients can obtain diagnosis, advice, and treatment under one roof, either in the surgery or at home. This is particularly helpful to rural patients who face long journeys to the nearest shops."

\section{Discount row}

A potent factor in the unrest among rural practitioners has been the discount inquiry. This inquiry was prompted by the doctors' and dentists' review body, which had discovered in 1983 that dispensing doctors' net average income was higher than that of non-dispensing doctors. The outcome in 1984 of discussions between the DHSS and the profession's negotiators on the discounts that wholesale drug suppliers gave to dispensing doctors had been a technical agreement, often misunderstood by doctors, claimed Dr Farrow.

Dispensing doctors will be receiving by 1 April 1985 direct reimbursement of the net ingredient cost of the drugs they dispense with the application of the full $5 \%$ sliding discount scale regardless of whether or not the suppliers offer a discount. The previous resultant net extra income had been to the detriment of their non-dispensing colleagues because the total expenses for drug purchases form part of the overall pool of NHS general practitioners' expenses, which was accordingly reduced for distribution to all general practitioners.
Dr Farrow described his objectives for rural practice as:

- Improving the lot of isolated singlehanded rural practitioners.

- Consolidating the achievements of the Clothier agreement at local level.

- Improving relations and developing mutual trust with the pharmacists, and in the interests of patients isolating extremists in both professions.

- Strengthening communication with rural practitioners through better use of professional publications and by encouraging members of the rural practices subcommittee to improve contacts with constituents and local medical committees.

- Maintaining the rural practice fund and dispensing remuneration on a fair and equitable basis.

- Making himself freely available to answer criticisms and hear advice and helping the GMSC secretariat to develop a rural practice information service.

The 22 members of the rural practices subcommittee, 14 of them members of the General Medical Services Committee, include representatives from all regional groupings of local medical committees in the United Kingdom. The membership of the subcommittee is given in appendix VII (page 35) of the GMSC's annual report for 1984-5, which has recently been sent to all NHS general practitioners.

The technical complexities of the reimbursement of general practitioners' expenses-and in particular those concerning dispensing payments-have probably contributed to the profession's lack of understanding about what has happened. As Dr Farrow observed, reports on the subject do not make easy reading. The consequence has been that until the cut in the reimbursable net ingredient cost affected their monthly pay cheques most dispensing doctors were unaware that the information they had been given would actually mean a change in their net remuneration. Understandably, the reduction in income, however justified, has not been welcomed. The resultant row was, declared Dr Farrow, a prime example of what happened when there was a communications gap between the ordinary rural doctor and his representatives. It is a gap he is determined to bridge. But he warned that local medical committees and $N$ individual doctors must accept a share of the blame for poor communication.

One consequence of the ignorance about Clothier and the cut $\bar{N}$ in reimbursement for discount drugs had been the birth of the N Dispensing Doctors Association, which claimed that the GMSC was not properly representing the interests of rural doctors. $\mathrm{Dr}$ Farrow, who attended and spoke frankly at that association's first meeting, was sceptical of its founders' claim to have attracted $\stackrel{\oplus}{\rightarrow}$ 2000 or 3200 or so rural dispensing practitioners. He looked 0 forward to more communication initiatives to follow up the letter $\vec{D}$ that the chairman of the GMSC had sent to all rural doctors in $\stackrel{\mathbb{D}}{\circ}$ September 1984, such as open local medical committee meetings $\overrightarrow{\mathbb{D}}$ with regional representatives of the rural practices subcommittee attending.

Dispensing is only a part of rural practice so are the pro- $\frac{8}{0}$ fessional and financial rewards of rural practice adequate? There had been a change since he entered practice in the 1960s, 
Dr Farrow replied, a career that he admitted had started by chance but that he did not regret. Then doctors loved to come into rural practice with its cottage hospitals and attractive environment-the rewards were the lifestyle as much as the money. Nowadays, however, young doctors were more hard headed: they wanted to work in a partnership of at least three or four so that they had adequate time off. They were accustomed to rotas-one night on in four seemed to be the acceptable minimum-and incoming partners liked to be near a good state school, to be within reach of London or other cities, and did not want their wives involved in the practice. These criteria were hard to fulfil, with the last especially difficult, he said, because rural practice did make heavy demands on the doctor's family. But the financial rewards were on a par with those of comparable urban practices.

The change in doctors' attitudes saddened him, but he acknowledged that it was probably part of a wider social change towards more leisure time. Some new entrants were surprised that rural doctors still did their own minor surgery, but there had been a great change in obstetric practice from the days when, as he put it, "the family doctor sat sweating hard on a slow delivery at home." Now women went straight to hospital. To a question whether young doctors did not enjoy the greater clinical responsibilities of rural practice, his answer was frank. Too many young doctors seemed more interested in the style and state of their patients' records than about how the patients were, a characteristic for which he blamed, in part, the Royal College of General Practitioners.

Had that and the younger generation's predilection for off duty time swayed his partnership against joining vocational training schemes based on the town 15 miles away ? Up to a point, yes: the trainees were too far away to do night work, an essential part of training for rural general practice, where, he added sharply, deputising services did not operate. He queried, too, whether academic ability necessarily equipped a young doctor to handle an aggressive bull, change a wheel on a snow bound track, or disarm a deranged farmer wielding a shotgun. To him such events were a welcome challenge, part of the rich variety of rural practice-a view helped no doubt by his fitness, ensured by a continued active passion for squash and cricket. Certainly, he preferred his rural patients to their town bound cousins. A rural colleague of his had recently done an urban locum for a friend and on emerging from visiting a patient's house had discovered that his car had a flat tyre. The active young husband of the patient had refused to help to change it. Dr Farrow found that hard to swallow because in his practice the tyre would in all probability have been changed while he was inside seeing the patient.

Glancing out at the slowly lifting winter fog, he acknowledged that rural practice meant long milages-less now that radiopaging was commonplace-and sometimes difficult driving. It had taken him over an hour to visit an ill farmer the previous evening. But his urban colleagues had to put up with heavy traffic, difficult parking, and worst of all vandalism-an unwanted phenomenon he had experienced when attending the BMA's annual meeting at Manchester. Even so, he did not believe that the results of central negotiations fairly reflected the all round rugged commitments of rural doctors, who were becoming fed up with the lack of recognition for what they did and for being taken for granted.

One of his urgent negotiating objectives was a better deal for isolated singlehanded practitioners, and discussions with the DHSS had been well advanced when he took the chair. They were a group, he said, whom the Family Doctor Charter had not really helped because its main thrust had been to encourage partnerships. This had not been a great problem while the intrinsic attractions of rural practice remained, but times were changing and singlehanded practitioners were getting restless, and turnover in these practices was rising.

Acknowledging that the answer was not simply more money for these doctors, he warned that some money or a pair of hands had to be found to enable them to have more time off, not just for personal activities - an essential respite- but for postgraduate education. The government failed to appreciate the total commitment of these doctors and the effects on their families, and this angered Dr Farrow. Their worth must be recognised, possibly by a special boost in their basic practice allowance and special arrangements for locum cover. Apart from that he was determined to raise the profile of rural practice among local medical committees and at the GMSC. His other main objectives are listed in the box at page 1090.

\section{Baptism of fire}

On the latest medicopolitical crisis-the government's plan to control by legislation the prescribing of some NHS drugs -Dr Farrow was firmly behind the GMSC in its opposition. Though doctors' prescribing could certainly be improved rural doctors already, in effect, operated their own limited lists because, he pointed out, as a small business a dispensing practice could not afford to carry a large and varied stock of drugs. But parliament had approved the government's plan, and it was some consolation that the minister had decided to allow dispensing doctors to sell to their patients those drugs they needed in the course of treatment that could no longer be prescribed on the NHS. "In the interests of rural patients, who might be many miles from the nearest pharmacist, it was the only sensible decision," he added. Dr Farrow was reticent, however, when I aked whether his contacts with rural organisations, which he had been carefully fostering, had borne fruit and played a part in the minister's change of mind. (Originally, the Minister for Health had not favoured dispensing doctors selling drugs: pharmacists still oppose it.)

The limited list dispute had been a baptism of fire for the GMSC chairman and for Dr Farrow. What were his first impressions? Firstly, a hell of a lot of work is required and, secondly, the pressures from the media on the general practitioners' leaders is persistent and demanding. "You have to watch what you say." In more general terms he was sad that many doctors sneered at medicopoliticians. In his experience most were conscientious men and women doing their best for their colleagues in a rather thankless task-largely using their own time for the work. He was fortunate in having three cooperative partners who acknowledged that his two days a week spent on medicopolitics - not to mention mounds of weekend background reading - was essential if the job was to be done properly. (He spoke of several prominent past GMSC committee members who had faced difficulties in their practices because of the demands on their time.) Even so, the idea of relying on full time negotiators did not appeal to him. When sitting opposite the DHSS's negotiators there was no substitute for the doctor who was in practice, backed up of course by the BMA's full time staff. "On several occasions I have been able to quote personal experience to reinforce an argument, and if I have been up the night before a negotiating session that adds an edge to my arguments," he declared. A sentiment for civil servants to note.

\section{Rural Dispensing Committee}

Since the start of the NHS drugs have customarily been dispensed by pharmacists. Doctors were, however, allowed to dispense for their patients where the patient lived in a rural area more than one mile from a pharmacy or where a patient had difficulty in getting to a pharmacist because of distance or travel difficulties whether in an urban or rural environment. These arrangements occasionally caused problems, one of the main ones being when sudden changes occurred in a rural area either because a pharmacy closed or opened or because a practice started, extended, or stopped dispensing. Such changes could 
affect the viability of a dispensing practice or make a pharmacist's business uneconomic. In either case services to patients could be adversely affected.

Persisting difficulties between the two professions led to the establishment in 1972 of a joint professional committee under an independent chairman, $\mathrm{Mr}$ (now Sir) Cecil Clothier QC. The committee, which contained five doctors, nominated by the General Medical Services Committee, and five pharmacists, took a long time to produce recommendations, which were finally published in 1980 , though it was 1983 before the two professions and the Department of Health and Social Security finally reached agreement on the necessary statutory framework to implement the new arrangements. In addition it was agreed that each profession would set up a voluntary fund based on contributions from local pharmaceutical or medical committees to compensate pharmacists or doctors adversely affected by decisions of the Rural Dispensing Committee. The doctors' fund had been slow getting off the ground but is now in operation.

The most important proposal was that significant changes in rural dispensing arrangements should be regulated by an independent statutory body consisting of three doctors, three pharmacists, and three lay members and a lay chairman, all appointed by the Secretary of State. In its first annual report, published in September 1984, the Rural Dispensing Committee describes the new regulations as providing a framework that "Removes from pharmacists the absolute right to begin dispensing anywhere. Instead, opening a new pharmacy in a rural area requires the consent of the committee. There is a provision to enable a pharmacist to discover whether a formal application would succeed by seeking preliminary consent.

"Removes from doctors the absolute right to begin or extend dispensing in rural areas. A doctor who wishes to do so must first obtain outline consent from the committee in respect of the area concerned.

"Allows the committee when approving proposals (whether from doctors or pharmacists) to stage their introduction over a period.

"Provides for family practitioner committees to establish dispensing subcommittees and for the subcommittees to exercise the rural dispensing functions on behalf of family practitioner committees, although family practitioner committees are empowered to require the subcommittees to refer matters for decision to them.

"Provides for the committee to hear appeals against a family practitioner committee's decision that an area is or is not rural.

"Provides for appeals to the Secretary of State for Social Services or the Secretary of State for Wales against decisions of the committee (except on questions of rurality, when there is no appeal from the decision of the committee)."

In its first year of operation (1 April 1983 to 31 March 1984) the committee received 54 applications from general medical practices for outline consent during the year, of which four were withdrawn, 21 were granted in full, eight were granted in part only, three were refused, and 18 had not been decided at 31 March 1984 improvement in career prospects and that if demand for doctors falls these could deteriorate further.

The committee's report, not surprisingly, is hedged by caveats, and it clearly shows that the business of predicting supply and demand is fraught with difficulties. At the same time as it published the report the government announced controls on the entry to the United Kingdom of overseas doctors. What other changes it will make in response to this report (which was based largely on 1980 figures) is uncertain, but it was predictable that "further study" would be called for and also that it recommends that the DHSS should continue to monitor the projected numbers carefully and regularly. The report also emphasises the need to take particular stock of the assumptions that have been made on the supposed increase in the activity of women doctors, the migration pattern for the UK and overseas born doctors, and the loss of graduates from an active career in medicine.

Membership of the committee included representatives of the health departments (Dr M E Abrams, Mr P Benner, Mr A Burchell, Mr M G Lillywhite, Mr A R Smith, Dr D J Anderson, Dr G Scott, and Dr C Hall); members nominated by the medical profession (Dr A S Blyth, Dr K Dalzell, Dr G H Hall, Mr J Kyle, Sir John Nabarro, Professor J P Payne, Dr M Rees, and Dr M A Wilson); and Professor D J Bartholomew, Professor J Parkhouse, and Dr W J E McKee. The committee was chaired by the Deputy Chief Medical Officer, Dr G R Ford.

\section{Reference}

1 Department of Health and Social Security. Report of the advisory committee for medical manpower plannng.
London: DHSS, 1985 .

\section{General management in Scotland}

The 15 Scottish health boards have been asked to appoint general managers by the end of 1985. In mainland boards the general manager posts will be new full time posts and recruitment will be by open advertisement. The islands boards will select a general manager from their existing chief officers, and general management duties will be performed in addition to that officer's existing functions.

The Secretary of State for Scotland issued a consultative paper in June 1984. ${ }^{1}$ The Scottish Home and Health Department has now issued a circular setting out the first steps in implementing in Scotland the recommendations of the NHS management inquiry. ${ }^{2}$ Most of the responses to the consultative paper favoured the introduction of the general management function. The arrangements at unit level will be announced after a study of unit management which the Department will commission.

Announcing the implementation, the Secretary of State for Scotland, Mr George Younger said:

"To enable my department to provide the necessary guidance on strategic tasks and targets and to monitor the National Health Service's performance I have created a new under secretary post with responsibility for NHS management, finance, and operational planning. I intend to establish a health service policy board, under the chairmanship of the Minister for Health and Social Work, to advise on policy decisions required for the health service in Scotland, the efficient management of the service, and the performance of the service in implementing agreed policy. The membership will include the chairman of the Scot- of tish health boards chairmen's group and the chairman of the Scottish Health Service Planning Council, together with my department's senior administrative and professional staff and the chief scientist. It will be supplemented as appropriate by the under secretary responsible for the social work services group."

\section{Programme of education and training}

The circular concludes:

"The introduction of board general $\frac{0}{3}$ managers will require a programme of education and training not only for the new appointees, but also for chairmen, members, chief officers, and medical and nursing staff. This is now being developed.

"Decisions made by clinicians have many $\sigma$ implications for priorities and resources for $\frac{D}{0}$ patient care. All clinicians therefore have an important part to play in the implementation $N$ of general management, even if they are not themselves general managers. Proposals will be $\omega$ developed for associating them with decision making by both boards and units within boards; and further advice will be forthcoming $\mathbb{D}$ in the context of the review of unit management and the evolution of management budgeting."

\section{References}

1 Scottish Home and Health Department. The general management function in the Nations SHHD, 1984.

Scottish Home and Health Department. General management in the Scottish health service: implementation-the first steps. Edinburgh: SHHD, 1985.

Published by the Proprietors, THE BRITISH MEDICAL ASSOCIATION, Tavistock Square, London WC1H 9JR, and printed in Great Britain by George Pulman and Sons Limited of London and Bletchley. Typesetting by Bedford Typesetters Limited, Bedford. 